\title{
Intraventricular rerouting for transposition of the great arteries with posterior aorta: Ventricular septal defect creation and total resection of the infundibular septum
}

\author{
Nobuyuki Ishibashi, MD, ${ }^{a}$ Mitsuru Aoki, MD, ${ }^{a}$ Manabu Watanabe, MD, ${ }^{a}$ Hiromichi Nakajima, MD, ${ }^{b}$
}

Hiroyuki Aotsuka, MD, ${ }^{\text {b }}$ and Tadashi Fujiwara, MD, ${ }^{a}$ Chiba, Japan

A

typical transposition of the great arteries (TGA), in which the aorta was situated posteriorly and the pulmonary artery (PA) was situated anteriorly, was reported in $1971 .^{1}$ In this TGA with a posterior aorta, the aorta rises from the right ventricle (RV) but retains fibrous aortic-mitral continuity, and the PA arises from a muscular conus above the left ventricle (LV). ${ }^{1,2}$ The principal surgical options are arterial or atrial switch combined with the ventricular septal defect (VSD) closure. ${ }^{3,4}$ In this anomaly, the VSD assumes a slit form, and the infundibular septum (IS) interferes with the LV-aorta route by the good alignment of the IS and the intraventricular septum (Figure 1, A), which makes the biventricular repair with intraventricular rerouting difficult in cases with pulmonary stenosis (PS).

We performed intraventricular rerouting by subpulmonary VSD creation and total resection of the IS for this disease complicated by PS (Figure 1,B). In this report, our procedure is described and discussed.

\section{Clinical Summary}

This boy was noted to be cyanotic and to have a heart murmur, and catheterization at the age of 10 months revealed D-TGA with a posterior aorta, small VSD, and PS. Because of the small size of subaortic VSD and the presence of additional muscular VSDs, biventricular repair was abandoned, and Damus-Kaye-Stansel anastomosis and a right modified Blalock-Taussig shunt was performed when the patient was aged 14 months. Catheterization at the age of 2 years 8 months demonstrated an LV and RV enddiastolic volume of $130 \%$ and $97 \%$ of normal, respectively; an LV and RV ejection fraction of $54 \%$ and $51 \%$, respectively; and natural closure of the muscular VSDs. On echocardiogram, mild regurgitation of the old pulmonary valve was noted, and VSD was $11.5 \times 7 \mathrm{~mm}$. Intraventricular rerouting was planned because of the progressive regurgitation of the old pulmonary valve, spontaneous closure of the muscular VSDs, and sufficient volume and function of the LV and RV.

\footnotetext{
From the Departments of Cardiovascular Surgery ${ }^{\mathrm{a}}$ and Cardiology, ${ }^{\mathrm{b}}$ Chiba Children's Hospital, Chiba, Japan.

Received for publication Jan 12, 2005; accepted for publication Jan 18, 2005.

Address for reprints: Nobuyuki Ishibashi, MD, Department of Cardiovascular Surgery, Chiba Children's Hospital, 579-1 Heta-cho, Midori-ku, Chiba-shi, Chiba 266-0007, Japan (E-mail: nobishibashi-ths@umin.ac.jp).

J Thorac Cardiovasc Surg 2005;130:593-4

$0022-5223 / \$ 30.00$

Copyright (C) 2005 by The American Association for Thoracic Surgery

doi:10.1016/j.jtcvs.2005.01.015
}

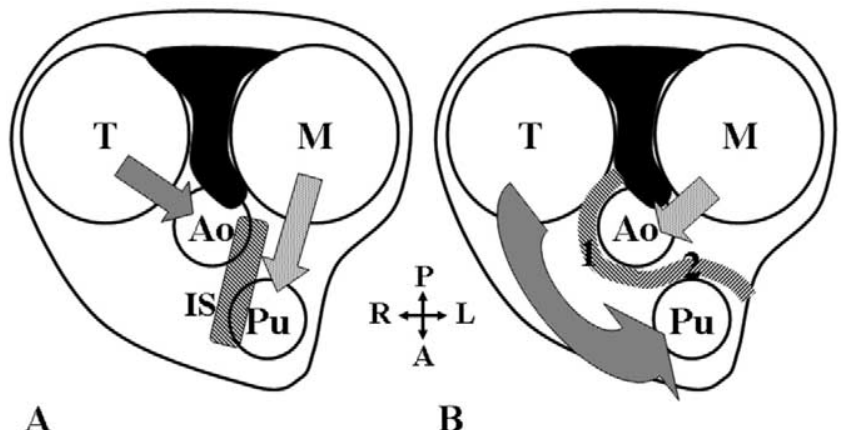

A

B

Figure 1. Schematic illustration of intraventricular rerouting by VSD creation and total resection of the infundibular septum. $A$, Before surgery. B, After surgery. Ao, Aortic valve; Pu, pulmonary valve; $M$, mitral valve; $T$, tricuspid valve; $I S$, infundibular septum; 1, LV outflow patch; 2 , RV outflow patch; $A$, anterior; $P$, posterior; $L$, left; $R$, right.

When the patient was 3 years old, we proceeded to operation with cardiopulmonary bypass. VSD was located in the outlet underneath the aortic valve, a slitlike muscular type, and a vestigial RV outflow tract-like structure was present anterior to the trabecula septomarginalis, although it was obliterated by a muscular bar (Figure 2, A). The Damus-Kaye-Stansel anastomosis was taken down, and a defect in the ascending aorta was closed with a polytetrafluoroethylene patch (Gore-Tex patch; W. L. Gore \& Associates, Inc, Flagstaff, Ariz). The aorta overrode the RV more than two thirds; however, there was a fibrous aortic-mitral continuity. Under the pulmonary valve, no dimple suggesting a vestigial connection to the RV was found. Through the tricuspid valve, the vestigial RV outflow tract was enlarged by muscle resection (Figure $2, B$ ) and connected to the subpulmonary area on the LV side by creating a defect in the IS (Figure $2, C$ ). The RV free wall was opened along the enlarged RV outflow tract. The created subpulmonary VSD was enlarged (Figure 2, D) and unified with the subaortic VSD by resection of the IS, thereby creating a large doubly committed VSD (Figure 2,E). Through the RV incision, intraventricular rerouting was performed by using 2 Gore-Tex patches. The 2-patch rerouting was designed as the LV outflow patch bulging toward the RV and the RV outflow patch bulging toward the LV (Figure 1, B, and Figure 2, F). Direct anastomosis was then made between the distal PA and the PA trunk, and transannular RV outflow tract reconstruction was made by using an autopericardial patch with an autopericardial monocusp. 

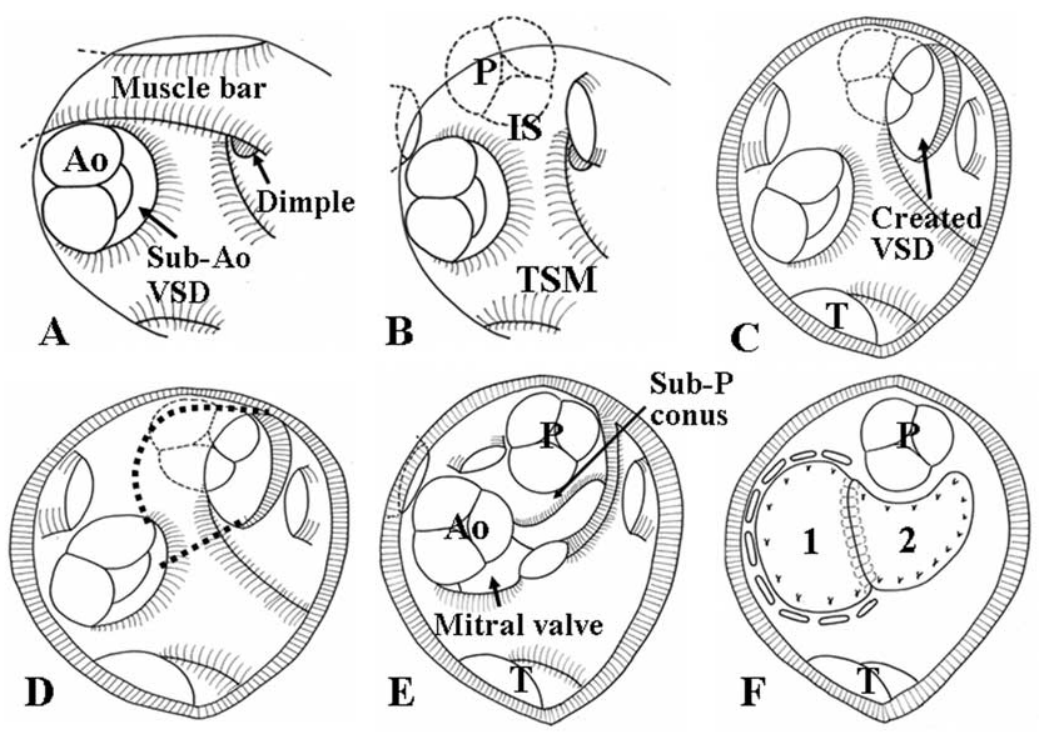

Figure 2. A, Anatomy through the tricuspid valve: the aorta overrode the RV more than two thirds, and the subpulmonary area did not connect to the RV. The vestigial RV outflow tract was present anterior to the TSM. B, Muscle bar resection and creation of the connection between the RV outflow tract and the subpulmonary area through the tricuspid valve. C, VSD creation through the RV incision. D, Enlargement of the created VSD with IS

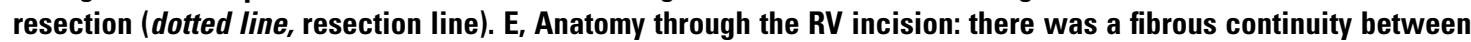
the aortic and the mitral valve. F, Intraventricular rerouting by using an LV outflow patch bulging toward the RV and an RV outflow patch bulging toward the LV. 1, LV outflow patch; 2, RV outflow patch; Ao, aortic valve; VSD, ventricular septal defect; $P$, pulmonary valve; $I S$, infundibular septum; $T S M$, trabecula septomarginalis; $T$, tricuspid valve.

The postoperative clinical course was uneventful. Catheterization at 10 months after the operation showed a widespread LV and $\mathrm{RV}$ outflow tract, an LV and RV ejection fraction of $51 \%$ and $49 \%$, respectively, right atrial pressure of $2 \mathrm{~mm} \mathrm{Hg}$, and normal $\mathrm{RV}$ pressure.

\section{Discussion}

This procedure has 2 essential features. The first is the creation of a connection between the RV outflow and the subpulmonary area at an appropriate location. In this patient, we noticed a dimple as a rudimentary $\mathrm{RV}$ outflow tract, and it was used as the landmark in creating the connection. The second is an IS resection sufficient for preventing long-term LV and RV outflow tract stenosis. We used 2 patches for intraventricular rerouting to create wide LV and RV outflow tracts.

Ventricular dysfunction is a concern in VSD creation and septal resection and is to be followed long term. However, we believe that the septal incision limited in the outlet portion of the septum reduces the risk of the $\mathrm{LV}$ outflow tract stenosis without ventricular dysfunction. In fact, in this case, good LV and RV ventricular function and low right atrial pressure ensure better long-term outcome than with the Fontan-type operation.

\section{References}

1. Van Praagh R, Perez-Trevino C, Lopez-Cuellar M, Backer FW, Zuberbuhler JF, Zuero M, et al. Transposition of the great arteries with posterior aorta, anterior pulmonary artery, subpulmonary conus and fibrous continuity between aortic and atrioventricular valves. Am J Cardiol. 1971;28:621-31.

2. Wilkinson JL, Arnold R, Anderson RH, Acerete F. 'Posterior' transposition reconsidered. Br Heart J. 1975;37:757-66.

3. Tam S, Murphy JD, Norwood WI. Transposition of the great arteries with posterior aorta. J Thorac Cardiovasc Surg. 1990;100:441-4.

4. Marin-Garcia J, Edwards J. Atypical d-transposition of the great arteries; anterior pulmonary trunk. Am J Cardiol. 1980;46:507-10. 